Research Article

\title{
Blood Eosinophils and Pulmonary Rehabilitation in COPD
}

\author{
Jafar Aljazeeri $\mathbb{D},{ }^{1,2}$ Abdullah Sakkat $\triangle{ }^{3}$ Nima Makhdami $\mathbb{D}^{4},{ }^{4}$ Rayyan Almusally, \\ Frederick Morfaw ${ }^{D},{ }^{6}$ and Andrew McIvor ${ }^{3,4}{ }^{3,4}$ \\ ${ }^{1}$ University of Pittsburgh Medical Center, Pennsylvania, USA \\ ${ }^{2}$ Drexel University College of Medicine, Pennsylvania, USA \\ ${ }^{3}$ McMaster University, Department of Medicine, Division of Respirology, Hamilton, Canada \\ ${ }^{4}$ Firestone Institute for Respiratory Health, St Joseph Healthcare, Hamilton, Canada \\ ${ }^{5}$ Imam Abdulrahman Bin Faisal University, Dammam, Saudi Arabia \\ ${ }^{6}$ McMaster Univerisity, Department of Health Research Methods, Evidence and Impact, Hamilton, Canada
}

Correspondence should be addressed to Jafar Aljazeeri; jafar.aljazeeri@medportal.ca

Received 23 August 2021; Accepted 24 October 2021; Published 5 November 2021

Academic Editor: Claudia Crimi

Copyright $(2021$ Jafar Aljazeeri et al. This is an open access article distributed under the Creative Commons Attribution License, which permits unrestricted use, distribution, and reproduction in any medium, provided the original work is properly cited.

Background. Blood eosinophils predict the response to therapy, risk of exacerbation, and readmission in COPD. This study investigates whether blood eosinophils predict pulmonary rehabilitation (PR) outcomes in COPD. Methods. We categorized patients into eosinophilic (blood eosinophils $\geq 300 \mathrm{cells} / \mathrm{ml}$ ) or noneosinophilic $(<300 \mathrm{cell} / \mathrm{s} / \mathrm{ml})$. In a retrospective design, we compared changes within and between the two groups on BODE index, 6-minute walk test (6MWT), FEV1, and mMRC dyspnea scale. Results. Of 206 patients enrolled, 176 were included for analysis; 90 were eosinophilic. BODE index improved in both groups: (MD $-1.25 ; 95 \% \mathrm{CI}(-0.45,-4.25), P \leq 0.001)$ in the eosinophilic and (MD $-1.33 ; 95 \% \mathrm{CI}(-1.72,-0.94), P \leq 0.001)$ in the noneosinophilic, but a higher BODE index remained in the eosinophilic (4.98); adjusted mean change ( $\beta): 0.7$ (95\% CI $(0.15,1.26)$, $P=0.01) .6$ MWT improved by $29.3 \mathrm{~m}$ in the eosinophilic (95\% CI $(14.2,44.4), P \leq 0.001)$ vs. $115.1 \mathrm{~m}$ in the noneosinophilic $(95 \%$ CI $(-30.4,260.6), P=0.12)$. FEV1 did not change in the eosinophilic (MD -0.6 ; $95 \% \mathrm{CI}(-2.64,1.48), P=0.58)$, but improved by $2.5 \%$ in the noneosinophilic (MD 2.5; 95\% CI $(0.77,4.17), P=0.005)$. There were no significant between-group differences in 6MWT and FEV1; adjusted mean changes $(\beta)$ were $-9.69 \mathrm{~m}(95 \% \mathrm{CI}(-39.51,20.14), P=0.52)$ and $-2.31 \%(95 \% \mathrm{CI}(-5.69,1.08)$, $P=0.18)$, respectively. There were no significant within- or between-group changes in the mMRC scale. Conclusion. Although PR improves the BODE index in both eosinophilic and noneosinophilic COPD, a higher eosinophil count ( $\geq 300$ cells/ml) is associated with a higher (worse) BODE index. Blood eosinophils may predict PR outcomes.

\section{Introduction}

Chronic obstructive pulmonary disease (COPD) is a progressive disease characterized by significant airflow limitation, lung destruction, and associated with chronic airway inflammation [1]. The pattern of inflammation in COPD is typically neutrophilic [2]; however, a subgroup of patients demonstrates high eosinophil levels, either in sputum or blood [3]. Although patients with eosinophilic phenotype exhibit the greatest response to corticosteroid therapy [4], several prospective studies suggest that eosinophilic inflammation is associated with an increased risk of exacerbation, readmission, and poor clinical outcomes [5-8].
The standard management of COPD consists of pharmacological and nonpharmacological treatments. Several recent studies have looked at the role of blood eosinophils in pharmacological treatment. For example, a post hoc analysis of 3 randomized trials showed that blood eosinophils can predict the effect of inhaled corticosteroids (ICS) in preventing future exacerbations when added to maintenance bronchodilator therapy [9]. Another pooled analysis of 2 trials found that adding roflumilast to combined bronchodilator therapy may reduce the risk of exacerbation in severe COPD with a greater benefit in patients with higher baseline eosinophil count [10]. Besides predicting the treatment effect, previous cohort studies have demonstrated 
that blood eosinophils can also predict future exacerbations $[8,11]$. On the other hand, scarce data, if any, exist as to whether blood eosinophils predict nonpharmacological treatment.

Pulmonary rehabilitation (PR) is a comprehensive integrated nonpharmacological intervention, a central component of the management of COPD, and recommended by most professional organizations and guidelines $[1,12]$. PR improves health status, dyspnea, and exercise tolerance and reduces hospitalization [13]. We also learned from prior studies that objective measurements, such as a 6-minute walk test (6MWT) and forced expiratory volume in 1 second (FEV1), improve after PR $[14,15]$. Beyond that, the ultrasound measurements of diaphragmatic mobility have shown a promising role of this noninvasive modality and may predict outcomes pre and post-PR in COPD patients [16]. However, it remains unknown whether a specific COPD phenotype (eosinophilic or noneosinophilic) benefits better than the other. Thus, we aimed to study the relationship between blood eosinophils and different measurable PR outcomes in COPD.

\section{Methods}

2.1. Study Design and Population. This is a retrospective observational cohort study. We extracted the study data from the electronic records database located in a universityaffiliated tertiary center, the Firestone Institute for Respiratory Health, McMaster University, Hamilton, Canada. We reviewed all patients admitted into the 6-week inpatient PR program between January 2010 and May 2016. This project was approved by the institutional ethics committee (Hamilton Integrated Research Ethics Board) and conducted according to the Declaration of Helsinki.

We included participants who were $\geq 40$ years of age, enrolled in the inpatient $\mathrm{PR}$ program with a primary documented diagnosis of COPD, based on symptoms, spirometry results, and the standard definition according to the Global Initiative for Chronic Obstructive Lung Disease and discharged alive from the program.

Exclusion criteria upon candidacy assessment were age $<40$ years, absence of fixed airflow limitation on spirometry results, never smokers, and enrollment for other obstructive pulmonary diseases (e.g. asthma and bronchiectasis), interstitial lung disease, pulmonary vascular disease, or prelung transplantation.

2.2. Data Collection. We collected baseline characteristic data: age, sex, smoking status, vaccination history, COPD therapy, home oxygen use, partial pressure of carbon dioxide (pCO2) level, use of walking aids, and blood eosinophil count level. Data for outcomes were collected at baseline and postrehabilitation and included: the body mass index (BMI)/ airflow obstruction/dyspnea/exercise capacity (BODE) index, distance walked in the 6-minute test (6MWT), the spirometry results of the force expiratory volume in 1 second (FEV1), and modified Medical Research Council (mMRC) dyspnea scale.
2.3. Study Variables and Outcomes. The principal independent variable was blood eosinophil cell count available at the time of admission or within the past 6 months of enrollment into the inpatient PR program. The cutoff $(\geq 300$ cells $/ \mathrm{ml}$ ) has previously shown a strong association with the risk of exacerbation and all-cause mortality in large epidemiological studies and post hoc analyses of clinical trials [9]. Thus, we considered this level to indicate the eosinophilic group. The outcomes of interest were the changes in the BODE index, 6MWT, FEV1, and mMRC dyspnea scale, within and between groups.

2.4. Statistical Analyses. We categorized patients into eosinophilic ( $\geq 300$ cells $/ \mathrm{ml}$ ) and noneosinophilic groups $(<300$ cells $/ \mathrm{ml}$ ). We compared changes in study variables between the two groups. We used the paired sample $t$-test to estimate the within-group changes (mean postrehabilitation minus mean at baseline) on the BODE index, 6MWT, and FEV1. The comparison of between-group differences in these outcomes was done by using multivariable linear regression. The independent variable was the eosinophil category, while the different outcomes (BODE index, 6MWT, and FEV1) served as the dependent variables. For the mMRC dyspnea scale, we categorized this outcome into a binary outcome (improved or not improved). We used logistic regression following PR between the two groups. All variables were adjusted for age, gender, current smoking status, history of smoking, the interaction between current smoking status and history of smoking, vaccination history, COPD treatment regimen, $\mathrm{BMI}, \mathrm{pCO}_{2}$ retainer status, home $\mathrm{O}_{2}$ therapy status, use of walking aids, and the respective baseline value for each outcome. All analyses were performed using SPSS version 25.0 [17].

\section{Results}

A total of 262 patients were admitted to the inpatient PR program during the data collection period between January 2010 and May 2016. Of them, 206 candidates met the inclusion criteria. Reasons for exclusion are shown in Figure 1. 176 patients had complete data, thus included for analysis. 90 patients (51.1\%) were eosinophilic (blood eosinophils $\geq 300$ cells $/ \mathrm{ml}$ ). Patients' baseline characteristics are given in Table 1.

3.1. BODE Index. The average baseline BODE index was 5.83 in the eosinophilic group, whereas 5.50 in the noneosinophilic group. In both groups, BODE index improved significantly post-PR (mean difference (MD) -1.25 ; $95 \% \mathrm{CI}$ $(-0.45,-4.25), P<0.001)$ in the eosinophilic group versus (MD -1.33 ; 95\% CI $(-1.72,-0.94), P<0.001)$ in the noneosinophilic group (Table 2). Post-PR analysis showed a higher mean BODE index in the eosinophilic group (4.98) when compared with noneosinophilic (4.17). After a fully adjusted analysis, the between-group comparison (eosinophilic vs. noneosinophilic) in the BODE index differed significantly post-PR (adjusted mean change $(\beta), 0.7$ (95\% CI (0.15-1.26)), $P=0.01$ ) (Table 3). 


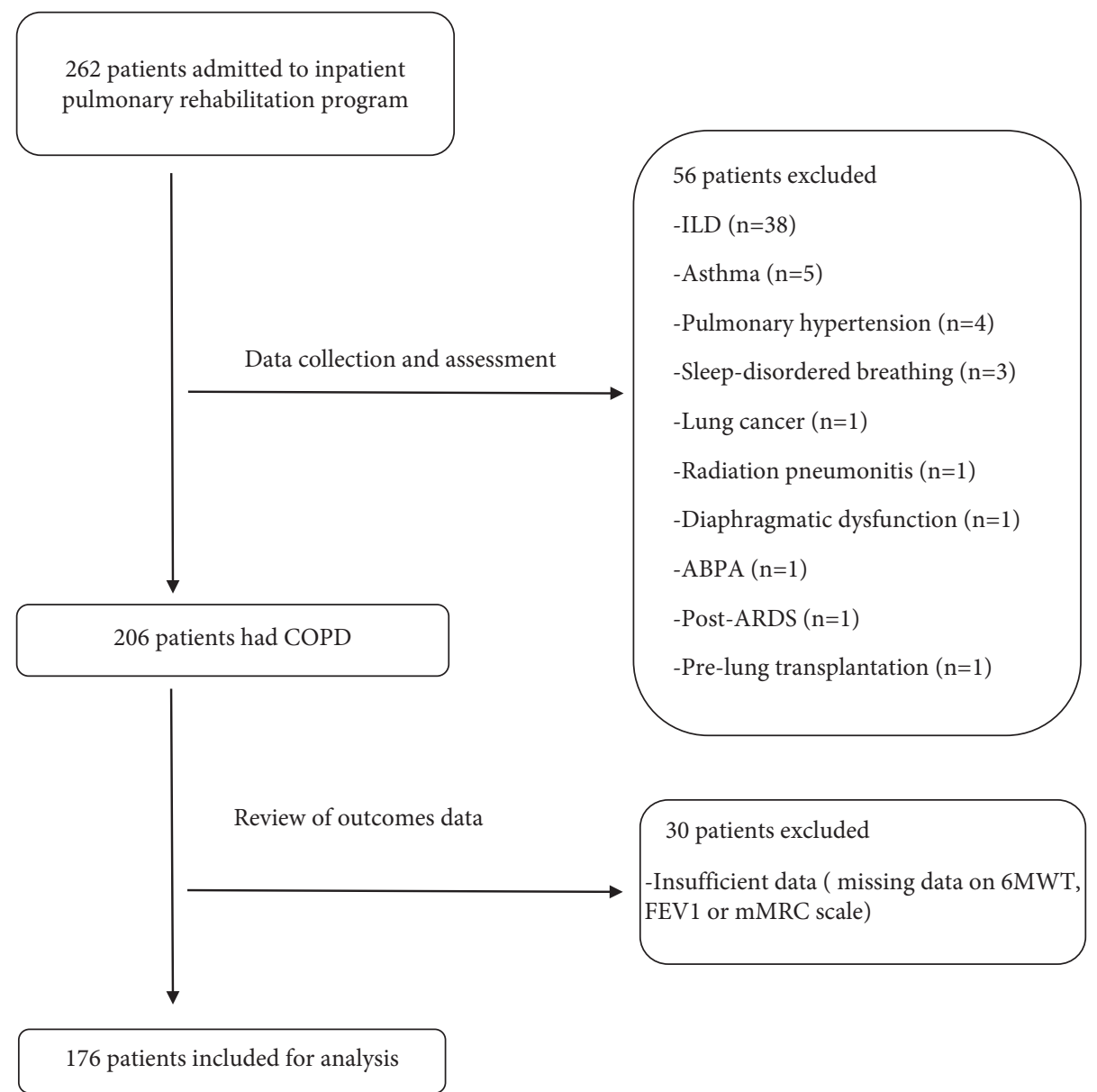

FIgURE 1: Flowchart of patients' enrollment process.

3.2. 6-Minute Walk Test. The average baseline total walked distanced in the eosinophilic group was 240 meters $(m)$ compared with $250 \mathrm{~m}$ in the noneosinophilic group. Post$\mathrm{PR}, 6 \mathrm{MWT}$ improved by $29.2 \mathrm{~m}$ (CI $(14.2,44.4), P \leq 0.001)$ in the eosinophilic group and by $115.1 \mathrm{~m}$ (CI $(-30.4,260.6)$, $P=0.12$ ) in the noneosinophilic group (Table 2). No significant between-group changes were in 6MWT: $-9.69 \mathrm{~m}$ (95\% CI $(-39.51,20.14), P=0.52$ ) (Table 3).

3.3. FEV1. The mean baseline FEV1 was $35.6 \%$ in the eosinophilic group versus $36.8 \%$ in the noneosinophilic group. No significant change in the mean FEV1 post-PR among the eosinophilic group (MD -0.6; 95\% CI (-2.64, 1.48), $P=0.58)$. However, we observed a mild increase of the mean FEV1 by $2.5 \%$ in the noneosinophilic group (MD 2.5; 95\% CI $(0.77,4.17), P=0.005)$ (Table 2$)$. FEV1 did not differ in between-group comparison; adjusted mean change $(\beta)$ is -2.31 (95\% CI $(-5.69,1.08), P=0.18)$ (Table 3).

3.4. $m M R C$. The mean mMRC dyspnea scale was nearly similar between both groups at baseline. Neither group showed improvement post-PR; $86.6 \%$ of the eosinophilic and $86.0 \%$ of the noneosinophilic had no improvement of the mMRC scale (Table 2). The odds of improvement in the
mMRC scale between both groups were not significant; adjusted OR was $1.21(95 \%$ CI $(0.17,8.13), P=0.84)$ (Table 3).

\section{Discussion}

The main finding of this study is that COPD with eosinophilic inflammation (defined as blood eosinophil count $\geq 300$ cells $/ \mathrm{ml}$ ) is associated with less favorable pulmonary rehabilitation (PR) outcomes when compared with their counterpart noneosinophilic ( $<300$ cells $/ \mathrm{ml})$. Although improved in both groups post-PR, we found a higher mean BODE index in the eosinophilic group. This impact of eosinophil counts on the BODE index is consistent after fully adjusted analyses on multiple variables. Other outcomes (6MWT, FEV1, and mMRC) did not differ between both groups, but we observed a trend of better performance in the noneosinophilic group.

The BODE index is a validated assessment tool that has a prognostic value for the risk of exacerbations and mortality in COPD $[18,19]$. The change in the BODE index predicts survival better than any changes of its individual components (mMRC, FEV1, 6MWT, and BMI) - an increase of BODE index $\geq 1$ is associated with increased mortality [20]. In our study, the BODE index improved in both groups by more than 1, and likely, both groups have benefited from the 
TABLE 1: Baseline characteristics of the study participants.

\begin{tabular}{|c|c|c|}
\hline Variables & Eosinophil count $\geq 300(n=90)$ & Eosinophil count $<300(n=86)$ \\
\hline Age (year), mean $\pm S D$ & $67.4 \pm 8.9$ & $67.7 \pm 12.0$ \\
\hline BMI $\left(\mathrm{kg} / \mathrm{m}^{2}\right)$, mean $\pm \mathrm{SD}$ & $24.4 \pm 7.3$ & $26.6 \pm 7.5$ \\
\hline \multicolumn{3}{|l|}{ Gender, $n(\%)$} \\
\hline Female & $42(46.7)$ & $37(43.0)$ \\
\hline Male & $48(53.3)$ & $49(57.0)$ \\
\hline \multicolumn{3}{|l|}{ Current smoking status, $n(\%)$} \\
\hline Smoker & $13(14.4)$ & $10(11.6)$ \\
\hline Pack-year & $50.1(25.1)$ & $58.7(23.0)$ \\
\hline \multicolumn{3}{|l|}{ Vaccination history, $n(\%)$} \\
\hline Influenza vaccine & $79(87.8)$ & $80(93.0)$ \\
\hline Pneumococcal vaccine & $66(73.3)$ & $54(62.8)$ \\
\hline \multicolumn{3}{|l|}{ COPD treatment, $n(\%)$} \\
\hline SABA & $87(96.7)$ & $79(91.9)$ \\
\hline SAMA & $6(6.7)$ & $5(5.8)$ \\
\hline ICS/LABA & $80(88.9)$ & $70(81.4)$ \\
\hline LAMA & $81(90.0)$ & $72(83.7)$ \\
\hline PDE4 inhibitor & $3(3.3)$ & $2(2.3)$ \\
\hline Systemic corticosteroids & $19(21.1)$ & $22(25.6)$ \\
\hline Macrolides & $4(4.4)$ & $5(5.8)$ \\
\hline \multicolumn{3}{|l|}{ Home $\mathrm{O}_{2}$ therapy } \\
\hline Yes & $58(64.4)$ & $45(52.4)$ \\
\hline \multicolumn{3}{|l|}{ Walking aids, $n(\%)$} \\
\hline Yes & $54(60.0)$ & $39(45.3)$ \\
\hline \multicolumn{3}{|l|}{$\mathrm{pCO}_{2}$ retainer, $n(\%)$} \\
\hline Yes & $39(43.3)$ & $34(39.6)$ \\
\hline $\mathrm{CO}_{2}$ level $(\mathrm{mmHg})$, mean $\pm \mathrm{SD}$ & $45.2 \pm 8.1$ & $45.9 \pm 10.1$ \\
\hline BODE index, mean $\pm S D$ & $5.8 \pm 2.1$ & $5.5 \pm 2.1$ \\
\hline $6 \mathrm{MWT}(\mathrm{m})$, mean $\pm \mathrm{SD}$ & $242.9 \pm 105.9$ & $247.3 \pm 110.4$ \\
\hline FEV1 (\%), mean \pm SD & $35.5 \pm 30.1$ & $36.9 \pm 16.7$ \\
\hline \multicolumn{3}{|l|}{ Dyspnea mMRC scale, $n(\%)$} \\
\hline 0 & $3(3.5)$ & $2(2.5)$ \\
\hline 1 & $6(7.1)$ & $11(13.6)$ \\
\hline 2 & $33(38.8)$ & $28(32.6)$ \\
\hline 3 & $18(21.2)$ & $22(25.6)$ \\
\hline 4 & $24(28.2)$ & $18(20.9)$ \\
\hline
\end{tabular}

Data are presented as mean $\pm \mathrm{SD}$ (standard deviation), $n$ (number), or \% (percentage). Pack-year is calculated by multiplying the number of packs of cigarettes smoked per day by the number of years the person has smoked. SABA, short-acting $\beta$-agonist; SAMA, short-acting muscarinic antagonist; ICS/LABA, inhaled corticosteroid/long-acting $\beta$-agonist; LAMA, long-acting muscarinic antagonist; PDE4, phosphodiesterase type 4; $\mathrm{O}_{2}$, oxygen; $\mathrm{pCO}_{2}$, partial pressure of carbon dioxide; $\mathrm{mmHg}$, millimeter mercury; BODE, body mass index, airflow obstruction, dyspnea, and exercise; 6MWT, 6-minute walk test; m, meter; mMRC, modified Medical Research Council.

TABLE 2: Within-group change on outcomes postpulmonary rehabilitation.

\begin{tabular}{|c|c|c|c|c|c|}
\hline Outcome & Eosinophils & Baseline, mean & Post-PR, mean & Mean difference $(95 \% \mathrm{CI})$ & $P$ value \\
\hline \multirow{2}{*}{ BODE index } & $\geq 300$ & 5.83 & 4.58 & $-1.25(-0.45,-4.25)$ & $<0.001$ \\
\hline & $<300$ & 5.50 & 4.17 & $-1.33(-1.72,-0.94)$ & $<0.001$ \\
\hline \multirow{2}{*}{ 6MWT (m) } & $\geq 300$ & 240.3 & 269.5 & $29.2(14.2,44.4)$ & $<0.001$ \\
\hline & $<300$ & 250.4 & 365.5 & $115.1(-30.4,260.6)$ & 0.12 \\
\hline \multirow{3}{*}{ FEV1 (\%) } & $\geq 300$ & 35.6 & 35.0 & $-0.6(-2.64,1.48)$ & 0.58 \\
\hline & $<300$ & 36.8 & 39.3 & $2.5(0.77,4.17)$ & 0.005 \\
\hline & & & No improvement (\%) & Improved (\%) & \\
\hline \multirow{2}{*}{ mMRC scale* } & $\geq 300$ & & 86.6 & 13.3 & $\mathrm{n} / \mathrm{a}$ \\
\hline & $<300$ & & 86.0 & 14.0 & $\mathrm{n} / \mathrm{a}$ \\
\hline
\end{tabular}

PR, pulmonary rehabilitation; CI, confidence interval; BODE, body mass index, airflow obstruction, dyspnea, and exercise capacity; 6MWT, 6-minute walk test; m, meters; FEV1, forced expiratory volume in 1 second; mMRC, modified Medical Research Council; n/a, not applicable. ${ }^{*}$ mMRC change measured as a proportion (\%).

PR program. However, the degree of improvement was higher in the noneosinophilic patients, leaving questions on why such improvement is not seen in the eosinophilic patients and how to improve their PR outcomes? Regardless, whether blood eosinophils are independent factors per se or whether eosinophilic inflammation is controlled or not, 
TABLE 3: Between-group change on outcomes postpulmonary rehabilitation.

\begin{tabular}{lccc}
\hline Outcome & Unadjusted $\beta(95 \% \mathrm{CI})$ & $P$ value & Adjusted $\beta(95 \% \mathrm{CI})$ \\
\hline Change in BODE index. & $0.68(0.04,1.30)$ & 0.04 & $0.70(0.15,1.26)$ \\
Change in 6MWT $(\mathrm{m})$ & $-15.02(-44.21,14.16)$ & 0.31 & $-9.69(-39.51,20.14)$ \\
Change in FEV1 $(\%)$ & $-2.31(-6.03,1.41)$ & 0.22 & $-2.31(-5.69,1.08)$ \\
\hline & Unadjusted OR $(95 \% \mathrm{CI})$ & & 0.52 \\
Change in mMRC scale & $0.95(0.40,2.24)$ & 0.91 & Adjusted OR (95\% CI) \\
\hline
\end{tabular}

CI, confidence interval; BODE, body mass index, airflow obstruction, dyspnea, and exercise capacity; 6MWT, 6-minute walk test; FEV1, forced expiratory volume in 1 second; OR, odds ratio. Variables adjusted for include age, gender, smoking status, history of smoking, the interaction between current smoking status and history of smoking, vaccination history, COPD treatment regimen, $\mathrm{BMI}, \mathrm{pCO}_{2}$ retainer status, home $\mathrm{o}_{2}$ therapy status, use of walking aids, and the respective baseline values for each outcome.

more attention is needed for this subgroup of COPD. Recently, many studies focused on targeted management of eosinophilic inflammation. For example, data from randomized controlled trials (RCTs) concluded that adding ICS is beneficial in controlling COPD with blood eosinophil count $(\geq 300$ cells $/ \mathrm{ml})$ and reducing future exacerbations $[9,21]$. Another data from 2 RCTs found that antiinterleukin 5 therapy (mepolizumab) might reduce the annual rate of moderate or severe exacerbations in patients with COPD and eosinophilic phenotype [22]. Following the results of our study, we might be able to improve PR outcomes if we control the eosinophilic inflammation. Indeed, we need further studies to understand if adding therapies to control eosinophilic inflammation improves PR outcomes in COPD with higher blood eosinophils.

While there are no significant between-group differences in other outcomes (FEV1, 6MWT, and mMRC), a greater within-group performance is seen in the noneosinophilic group. For instance, the mean FEV1 post-PR increased by $2.5 \%$, which mirrors the expected change in FEV1 from previous data [14]. The 6MWT improved by $115 \mathrm{~m}$ in the noneosinophilic group but was not statistically significant. This magnitude $(115 \mathrm{~m})$ is probably a skewed data distribution and is likely driven by the heterogeneity/wide confidence interval in this group. In contrast, the 6MWT in the eosinophilic group improved significantly post-PR but only by $29.2 \mathrm{~m}$. This resembles the minimal clinically important difference for the change in 6MWT based on previous consensus $[23,24]$, yet less than the average of improved distance $(62 \mathrm{~m})$ after COPD exacerbation estimated in a meta-analysis of 13 studies [15].

In this study, most patients in both groups experienced no improvement in their mMRC dyspnea scale. We attribute this finding to the insensitivity of the mMRC scale to change in response to therapeutic intervention, a common limitation of the mMRC scale, and particularly seen in moderate to severe COPD $[25,26]$. Our cohort represents mostly severe COPD, with an average baseline FEV1 of $36 \%$, and more than half of them were on home $\mathrm{O}_{2}$ therapy; thus, the mMRC scale expectedly tends to congregate between 3 and 4. We know from previous studies that perceived dyspnea usually improves following the PR program irrespective of the measurement tool used or the baseline mMRC scale $[27,28]$. Eventhough the mMRC scale is a simple tool and widely used for referral to PR, it is only appropriate for discriminative properties and less useful for evaluative properties when compared with multidimensional tools such as the Chronic Respiratory Disease Questionnaire (CRQ) and the St. George's Respiratory Questionnaire (SGRQ) [29]. Hence, practice guidelines recommend rather using a multidimensional tool for evaluating dyspnea outcomes after PR instead of using the mMRC scale [12].

Our study has several merits. It is the first, to our knowledge, that studied the association of a biomarker (blood eosinophils) with pulmonary rehabilitation. This permits a wider vision of care when providing nonpharmacological interventions to COPD patients. Besides, we fully adjusted important variables that might have influenced the targeted outcomes to minimize potential confounders. Nonetheless, the study is retrospective in nature, and the results should be interpreted with caution. It was conducted in a single center, which may restrict generalizability. Moreover, additional data on clinical followups and long-term assessments were missing. Last, the exact doses of ICS therapy were not available, but we know that a large proportion of patients were using ICS, and they were nearly similar (80-90\%) in both groups. We acknowledge that this might indicate an unclear status on whether the eosinophilic inflammation is adequately optimized. In such cases, where eosinophilic status is readily needed, we recommend that respiratory physicians consider using a pointof-care device to assess the blood eosinophil count during the initial PR visit, as this quick tool has shown reliable measurements [30]. Our study emphasizes that more attention to this subgroup of COPD is warranted. Future studies with larger samples are needed to clarify if blood eosinophils independently predict PR outcomes or if the results of this study merely represent under management of this subgroup. In the end, the results represent a motive for a better understanding of the role of blood eosinophils beyond the response to pharmacological interventions and promote future initiatives to enhance the optimal management of this progressively disabling disease.

\section{Conclusion}

In COPD, a blood eosinophil count $\geq 300$ cells $/ \mathrm{ml}$ is associated with less favorable pulmonary rehabilitation outcomes-substantially, this level is associated with a higher BODE index. The findings reaffirm the importance of appropriately phenotyping and managing COPD. Blood eosinophils may predict PR outcomes in COPD. 


\section{Data Availability}

The data used to support the findings of this study are available from the corresponding author upon request.

\section{Disclosure}

The preliminary results of this study were presented as an online poster at the 2020 International Conference and Annual Meeting of The American Thoracic Society (ATS 2020) in Philadelphia, May 2020, and the abstract was published in the Online Abstract Issue of ATS (pp. A7391A7391) [31].

\section{Conflicts of Interest}

The authors declare that they have no conflicts of interest.

\section{Authors' Contributions}

J. Aljazeeri conceptualized, designed the study, extracted, interpreted, and presented data, and wrote, critically discussed, and revised the manuscript. A. Sakkat extracted, interpreted, and discussed the data and participated in the manuscript writing and editing. N. Makhdami extracted and presented data and revised the manuscript. R. Almusally interpreted and discussed the data and discussed and revised the manuscript. F. Morfaw was responsible for statistical analysis, figures, and table design, and critical revision of the manuscript. A. McIvor designed the study, extracted and interpreted data, performed statistical analysis, and critically discussed and revised the manuscript.

\section{References}

[1] GOLD 2020, "Global strategy for the diagnosis, management and prevention of copd. Global initiative for chronic obstructive lung disease," Journal of Chronic Obstructive Pulmonary Disease, vol. 1, no. 1, pp. 105-141, 2020.

[2] P. J. Barnes, "Immunology of asthma and chronic obstructive pulmonary disease," Nature Reviews Immunology, vol. 8, no. 3, pp. 183-192, 2008.

[3] D. Singh, U. Kolsum, C. E. Brightling, N. Locantore, A. Agusti, and R. Tal-Singer, "Eosinophilic inflammation in COPD: prevalence and clinical characteristics," European Respiratory Journal, vol. 44, no. 6, pp. 1697-1700, 2014.

[4] M. Bafadhel, S. McKenna, S. Terry et al., "Blood eosinophils to direct corticosteroid treatment of exacerbations of chronic obstructive pulmonary disease," American Journal of Respiratory and Critical Care Medicine, vol. 186, no. 1, pp. 48-55, 2012.

[5] S. H. Siddiqui, A. Guasconi, J. Vestbo et al., "Blood eosinophils: a biomarker of response to extrafine beclomethasone/ formoterol in chronic obstructive pulmonary disease," American Journal of Respiratory and Critical Care Medicine, vol. 192, no. 4, pp. 523-525, 2015.

[6] S. Pascoe, N. Locantore, M. T. Dransfield, N. C. Barnes, and I. D. Pavord, "Blood eosinophil counts, exacerbations, and response to the addition of inhaled fluticasone furoate to vilanterol in patients with chronic obstructive pulmonary disease: a secondary analysis of data from two parallel randomised controlled trials," The lancet Respiratory medicine, vol. 3, no. 6, pp. 435-442, 2015.

[7] S. Couillard, P. Larivée, J. Courteau, and A. Vanasse, "Eosinophils in COPD exacerbations are associated with increased readmissions," Chest, vol. 151, no. 2, pp. 366-373, 2017.

[8] S. Vedel-Krogh, S. F. Nielsen, P. Lange, J. Vestbo, and B. G. Nordestgaard, "Blood eosinophils and exacerbations in chronic obstructive pulmonary disease. The Copenhagen General Population Study," American Journal of Respiratory and Critical Care Medicine, vol. 193, no. 9, pp. 965-974, 2016.

[9] M. Bafadhel, S. Peterson, M. A. De Blas et al., "Predictors of exacerbation risk and response to budesonide in patients with chronic obstructive pulmonary disease: a post-hoc analysis of three randomised trials," The Lancet Respiratory Medicine, vol. 6, no. 2, pp. 117-126, 2018.

[10] F. J. Martinez, K. F. Rabe, P. M. A. Calverley et al., "Determinants of response to roflumilast in severe chronic obstructive pulmonary disease. Pooled analysis of two randomized trials," American Journal of Respiratory and Critical Care Medicine, vol. 198, no. 10, pp. 1268-1278, 2018.

[11] J. H. Yun, A. Lamb, R. Chase et al., "Blood eosinophil count thresholds and exacerbations in patients with chronic obstructive pulmonary disease," The Journal of Allergy and Clinical Immunology, vol. 141, no. 6, pp. 2037-e10, 2018.

[12] M. A. Spruit, S. J. Singh, C. Garvey et al., "An official American Thoracic Society/European Respiratory Society statement: key concepts and advances in pulmonary rehabilitation," American Journal of Respiratory and Critical Care Medicine, vol. 189 , no. 12 , p. 1570, 2014.

[13] C. E. Bolton, E. F. BevanSmith, J. D. Blakey et al., "British thoracic society pulmonary rehabilitation guideline development group; British thoracic society standards of care committee. British thoracic society guideline on pulmonary rehabilitation in adults: accredited by NICE," Thorax, vol. 68, pp. ii1-ii30, 2013.

[14] B. McCarthy, D. Casey, D. Devane, K. Murphy, E. Murphy, and Y. Lacasse, "Pulmonary rehabilitation for chronic obstructive pulmonary disease," Cochrane Database of Systematic Reviews, vol. 2, Article ID CD003793, 2015.

[15] M. A. Puhan, E. Gimeno-Santos, C. J. Cates, and T. Troosters, "Pulmonary rehabilitation following exacerbations of chronic obstructive pulmonary disease," Cochrane Database of Systematic Reviews, vol. 12, Article ID CD005305, 2016.

[16] C. Crimi, E. Heffler, T. Augelletti et al., "Utility of ultrasound assessment of diaphragmatic function before and after pulmonary rehabilitation in COPD patients," International Journal of Chronic Obstructive Pulmonary Disease, vol. 13, pp. 3131-3139, 2018.

[17] IBM Corp Released, IBM SPSS Statistics for Windows, Version 25.0, IBM Corp, Armonk, NY, USA, 2017.

[18] B. R. Celli, C. G. Cote, J. M. Marin et al., "The body-mass index, airflow obstruction, dyspnea, and exercise capacity index in chronic obstructive pulmonary disease," New England Journal of Medicine, vol. 350, no. 10, pp. 1005-1012, 2004.

[19] J. M. Marin, S. J. Carrizo, C. Casanova et al., "Prediction of risk of COPD exacerbations by the BODE index," Respiratory Medicine, vol. 103, no. 3, pp. 373-378, 2009.

[20] F. J. Martinez, M. K. Han, A.-C. Andrei et al., "Longitudinal change in the BODE index predicts mortality in severe emphysema," American Journal of Respiratory and Critical Care Medicine, vol. 178, no. 5, pp. 491-499, 2008. 
[21] D. A. Lipson, F. Barnhart, N. Brealey et al., "Once-daily singleinhaler triple versus dual therapy in patients with COPD," New England Journal of Medicine, vol. 378, no. 18, pp. 1671-1680, 2018.

[22] I. D. Pavord, P. Chanez, G. J. Criner et al., "Mepolizumab for eosinophilic chronic obstructive pulmonary disease," New England Journal of Medicine, vol. 377, no. 17, pp. 1613-1629, 2017.

[23] S. J. Singh, M. A. Puhan, V. Andrianopoulos et al., "An official systematic review of the European Respiratory Society/ American Thoracic Society: measurement properties of field walking tests in chronic respiratory disease," European Respiratory Journal, vol. 44, no. 6, pp. 1447-78, 2014.

[24] A. E. Holland, M. A. Spruit, T. Troosters et al., "An Official European Respiratory Society/American Thoracic Society technical standard: field walking tests in chronic respiratory disease," European Respiratory Journal, vol. 44, no. 6, pp. 1428-46, 2014.

[25] A. L. Ries, "Impact of chronic obstructive pulmonary disease on quality of life: the role of dyspnea," The American Journal of Medicine, vol. 119, no. 10, pp. 12-20, 2006.

[26] P. Meek, R. Schwartzstein, L. Adams et al., "Dyspneamechanisms, assessment, and management: a consensus statement," American Journal of Respiratory and Critical Care Medicine, vol. 159, no. 1, pp. 321-340, 1999.

[27] J. P. De Torres, V. Pinto-Plata, E. Ingenito et al., "Power of outcome measurements to detect clinically significant changes in pulmonary rehabilitation of patients with COPD," Chest, vol. 121, no. 4, pp. 1092-1098, 2002.

[28] R. A. Evans, S. J. Singh, R. Collier, J. E. Williams, and M. D. L. Morgan, "Pulmonary rehabilitation is successful for COPD irrespective of MRC dyspnoea grade," Respiratory Medicine, vol. 103, no. 7, pp. 1070-1075, 2009.

[29] T. Oga, M. Tsukino, T. Hajiro, A. Ikeda, and K. Nishimura, "Analysis of longitudinal changes in dyspnea of patients with chronic obstructive pulmonary disease: an observational study," Respiratory Research, vol. 13, no. 1, p. 85, 2012.

[30] E. Heffler, G. Terranova, C. Chessari et al., "Point-of-care blood eosinophil count in a severe asthma clinic setting," Annals of Allergy, Asthma, \& Immunology, vol. 119, no. 1, pp. 16-20, 2017.

[31] J. Aljazeeri, N. Makhdami, A. Sakkat, F. Morfaw, and A. McIvor, "Eosinophilic chronic obstructive pulmonary disease and pulmonary rehabilitation outcomes: a singlecenter study. InD68. Clinical characteristics and risk stratification," in Pulmonary Rehabilitation, p. A7391, American Thoracic Society, New York, NY, USA, 2020. 